Journal of Patient-Centered

\title{
Seroprevalence of COVID-19 IgG Antibody in Resident and Fellow Physicians in Milwaukee, Wisconsin: Analysis of a Cross- Sectional Survey
}

\author{
Dennis J. Baumgardner \\ Alexander Schwank \\ Jessica J. F. Kram \\ Wilhelm Lehmann \\ Jacob Bidwell \\ Tricia La Fratta \\ Kenneth Copeland
}

Follow this and additional works at: https://aah.org/jpcrr

Part of the Diagnosis Commons, Family Medicine Commons, Health Services Administration

Commons, Medical Education Commons, Medical Immunology Commons, Occupational Health and Industrial Hygiene Commons, and the Virus Diseases Commons

\section{Recommended Citation}

Baumgardner DJ, Schwank A, Kram JJ, Lehmann W, Bidwell JL, La Fratta T, Copeland K. Seroprevalence of COVID-19 IgG antibody in resident and fellow physicians in Milwaukee, Wisconsin: analysis of a crosssectional survey. J Patient Cent Res Rev. 2022;9:75-82. doi: 10.17294/2330-0698.1846

Published quarterly by Midwest-based health system Advocate Aurora Health and indexed in PubMed Central, the Journal of Patient-Centered Research and Reviews (JPCRR) is an open access, peer-reviewed medical journal focused on disseminating scholarly works devoted to improving patient-centered care practices, health outcomes, and the patient experience. 


\title{
Seroprevalence of COVID-19 IgG Antibody in Resident and Fellow Physicians in Milwaukee, Wisconsin: Analysis of a Cross-Sectional Survey
}

\author{
Dennis J. Baumgardner, MD, , ${ }^{1,2}$ Alexander Schwank, MPH, ${ }^{1,2}$ Jessica J. F. Kram, MPH, ${ }^{1,2,3}$ Wilhelm \\ Lehmann, MD, ${ }^{1,3}$ Jacob L. Bidwell, MD, ${ }^{1,3}$ Tricia La Fratta, MBA, ${ }^{1}$ Kenneth Copeland, $\mathrm{PhD}^{4}$ \\ ${ }^{1}$ Aurora UW Medical Group, Advocate Aurora Health, Milwaukee, Wl; ${ }^{2}$ Center for Urban Population Health, Milwaukee, \\ WI; ${ }^{3}$ Department of Family Medicine and Community Health, University of Wisconsin School of Medicine and Public \\ Health, Madison, WI; ${ }^{4}$ ACL Laboratories, Advocate Aurora Health, Milwaukee, WI
}
Purpose $\quad$ Medical trainees are likely at differential risk of exposure to COVID-19 per respective clinical activity. We sought to determine the seroprevalence of COVID-19 antibody (Ab) among resident and fellow physicians with varying degrees of exposure to COVID-19.
Methods A cross-sectional study of Milwaukee-based resident and fellow physicians, encompassing December 2019-June 2020, was conducted. Relevant variables of interest were ascertained by survey and payroll data, and Abbott ARCHITECT Ab test (index cut-off of $\geq 1.4$ ) was performed. Descriptive statistics were generated, with $95 \% \mathrm{Cl}$ calculated for the study's primary outcome of seroprevalence.

Results $\quad$ Among survey respondents (92 of 148, 62\%), 61\% were male, 44\% were non-White, mean age was 31 years, $94 \%$ had no underlying conditions, and $52 \%$ were either family or internal medicine residents. During the study period, $\geq 32 \%$ reported cough, headache, or sore throat and $62 \%$ traveled outside of Wisconsin. Overall, 83\% thought they had a COVID-19 exposure at work and 33\% outside of work; $100 \%$ expressed any exposure. Of those exposed at work, 56\% received COVID-19 pay, variously receiving 69 mean hours (range: 0-452). Ultimately, 82\% (75 of 92) had an Ab test completed; 1 individual (1.3\%; 95\% Cl: 0.0-3.9) tested seropositive, was not previously diagnosed, and had received COVID-19 pay.

Conclusions The low Ab seroprevalence found in resident and fellow physicians was similar to the concurrently reported 3.7\% Ab-positive rate among 2456 Milwaukee-based staff in the same integrated health system. Ultimately, COVID-19 seroconversion may be nominal in properly protected resident and fellow physicians despite known potential exposures. (J Patient Cent Res Rev. 2022;9:75-82.)

Keywords coronavirus infections; SARS-CoV-2; COVID-19; education, medical, graduate; antibodies, viral

\begin{abstract}
A s of December 2021, the COVID-19 infection caused by severe acute respiratory syndrome coronavirus 2 (SARS-CoV-2) has resulted in approximately 50 million cases and 800,000 deaths in the United States. ${ }^{1}$ Early on, the etiologic virus was challenging to predict, control, and track. ${ }^{2-4}$ For obvious reasons, health care workers, including physicians, are at higher risk for acquisition of COVID-19. ${ }^{5}$ These individuals also can be exposed outside of the work environment, especially given the significant percentage of spread from presymptomatic and asymptomatic individuals..$^{6,7}$
\end{abstract}

Corresponding author: Dennis J. Baumgardner,

960 N. 12th St., Milwaukee, WI, 53233

(dennisj.baumgardner@outlook.com)
In most integrated health systems, resident and fellow physicians provide frontline care to inpatients and outpatients in many departments, and their safety is the responsibility of the institution. ${ }^{8}$ Similar to other health care workers, residents and fellows are likely at differential risk of exposure to COVID-19 based on the specific clinical activities in which they engage. ${ }^{7}$ The impact of the COVID-19 pandemic on operations and continuing accreditation of residencies and fellowships is

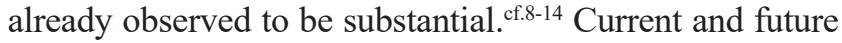
protection of these trainees, as well as their co-workers and family, is vitally important.

The role of serology is essential for understanding COVID-19 past exposure and future planning. ${ }^{15,16}$ Currently, it is still being determined what level of antibody response confers immunity and how long it may last. ${ }^{17-19}$ In Wisconsin, at the time of study initiation, limited testing 
for acute COVID-19 infection had been positive in $9 \%$ of all individuals tested and $12 \%$ of all health care workers tested; $10.5 \%$ of statewide COVID-19 immunoglobulin $\mathrm{G}$ ( $\mathrm{IgG}$ ) antibody (Ab) tests performed for various reasons were positive (internal data on file May 11, 2020). The percentage of our own institution's residents and fellows who had contracted COVID-19 infection (including asymptomatic, presymptomatic, and minimally symptomatic disease) was also unknown at the time.

Therefore, this study's primary aim was to determine the overall seroprevalence of COVID-19 IgG Ab in relatively young, healthy adults who are resident and fellow physicians. We also wished to determine the seroprevalence of $\mathrm{Ab}$ in these individuals by specialty type, associations of positive $\mathrm{Ab}$ tests by degree and types of clinical activities, and number of known exposures to COVID-19 patients or persons outside of the work setting. We hypothesized that the overall seroprevalence of COVID-19 IgG Ab among residents and fellows would be higher than that of the general population of similar age in the surrounding community and that the seroprevalence would differ by type of clinical activity subjects were involved. As this study was set in a city (Milwaukee, Wisconsin) during a time of medium risk (June 2020), we believe the results to be generalizable to other U.S.-based training sites and hence may inform graduate medical education program directors, institutional officials, and oversight bodies such as the Accreditation Council for Graduate Medical Education (ACGME) of the (perhaps differential) risk of trainee infection with COVID-19.

\section{METHODS}

\section{Study Population, Design, Data Sources}

This targeted, cross-sectional study aimed to estimate the seroprevalence of COVID-19 viral infection ${ }^{20}$ among all residents and fellows employed by a single integrated health system and based in Milwaukee, Wisconsin $(n=148)$. Similar to other institutions, many of the medical trainees in generalist or specialty programs were redeployed to cover or perform extra inpatient duties, including care of COVID-19 patients. ${ }^{810}$ These individuals were afforded appropriate personal protective equipment (PPE), including gowns, face shields, and N95 respirators.

Subjects were asked to voluntarily participate in the study, irrespective of training program, primary clinical setting, and relevant demographics. This study received local institutional review board approval, and subjects acknowledged informed consent information embedded within the initial pages of the survey.

Participants were invited by the manager of research for our system's graduate medical education department via email on June 5, 2020, to complete the online survey using REDCap, a mature, secure web application for building and managing online surveys and databases. ${ }^{21,22}$ Those among the 148 residents and fellows who did not acknowledge consent for participation, who indicated they were not based in Milwaukee, or who did not participate in a program within the last 8 training program block intervals were excluded. The survey queried respondents regarding the 84 -week duration curriculum rotation block intervals within the time period of December 2019 to June 2020 and collected demographic characteristics, working conditions, household size, previous clinical symptoms, preexisting medical conditions, working conditions by time period, household size, known COVID-19 exposures, acute COVID-19 testing history and results, subject Ab test result prediction, desires for a positive versus negative test result, and reasons for desiring a particular result. Additionally, the timing by rotation block and number of hours of special COVID-19 pay received during the survey time period was linked to each completed survey by the research manager for the last 4 blocks.

\section{Antibody Assay}

Following survey completion, participants were sent a requisition to complete an $\mathrm{Ab}$ test if they had not already completed one. Willing subjects had a SARS-CoV-2 (nucleocapsid protein) IgG Ab test (ARCHITECT ${ }^{\circledR}$, Abbott) $^{-}$ performed on their serum in our health system laboratory per manufacturer protocol. Tests were drawn during JuneJuly 2020. Results and the index value (numerical test result) were recorded for each test; a value of $\geq 1.4$ was considered seropositive per manufacturer specifications. All test results regardless of positivity were reported to the appropriate health department and to the subjects.

\section{Statistical Analysis}

The primary outcome of interest for this study was to estimate seroprevalence of COVID-19 antibodies among all eligible and willing resident and fellow physicians. The minimum sample size was determined by the previous surveillance of COVID-19 within our health system at study onset. Using the then-estimated seroprevalence of $10.5 \%$ (internal data on file May 8,2020 ), we needed to enroll an estimated minimum of 78 participants in order to estimate the true population proportion of COVID-19 seroprevalence, with a required margin of error of $5 \%$ and a confidence level of $95 \%$. A finite population correction was applied to the sample size formula. Descriptive statistics were performed to describe the demographic characteristics and outcome of study participants. Frequencies were calculated with $95 \%$ CI, as appropriate by variable type and the distribution of values, and potential associations analyzed by simple linear regression. 


\section{RESULTS \\ Survey Results}

The overall survey response rate was $62 \%$ (92 of 148 , Figure 1). Survey responses varied by program type and training year (Table 1). Demographic details of the surveyed residents and fellows are presented in Online Supplemental Table S1. Most subjects had no underlying chronic illnesses, and the minority reported symptoms typical of acute symptomatic COVID-19 infection, ${ }^{23}$ none of which were apparently severe (Online Supplemental Table S2).

Table 2 details the exposure histories of those surveyed. Only one individual reported a history of positive polymerase chain reaction test results for COVID-19. All reported some type of exposure, with the majority $(83 \%)$ reporting patient exposures, and fewer reporting

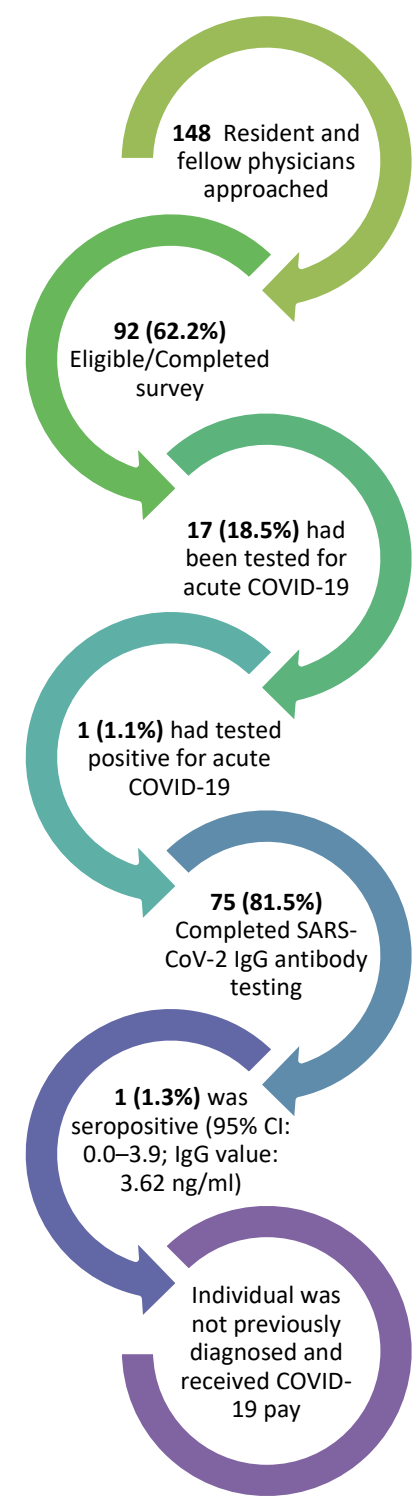

Figure 1. Breakdown of resident and fellow physicians approached to participate. household $(22 \%)$ or other exposures $(33 \%)$. Travel outside of Wisconsin was common during the time period; $61 \%$ of participants traveled during blocks before the state-issued lockdown (November 18, 2019-March 8, 2020 ) and $26 \%$ during blocks after the lockdown.

Table 3 describes the number of encounters with COVID-19-positive patients by training program. Special duty COVID-19 pay was used as a proxy for patient exposure, and it was variously received by 40 trainees in this study between March 9, 2020, and June 30, 2020. Online Supplemental Table S3 depicts aggregate receipt of hours of this special pay by trainee specialty; unsurprisingly, internal medicine residents accumulated the most hours. Figure 2 illustrates hours of COVID-19 pay by the number of reported COVID-19-positive patient encounters for the 40 subjects who received it. The association was statistically significant but explains a minority of the variation.

Of 92 survey respondents, 16 (17\%) believed they had COVID-19 sometime during the study period. In addition, 18 of $92(19 \%)$ were previously tested for acute COVID-19, of which 1 tested positive (this person

Table 1. Response Rate to Survey Invitation by Postgraduate Year and Training Program $(\mathrm{N}=148)$

\begin{tabular}{lc}
\hline Respondent status & $\mathbf{n}(\%)$ \\
\hline Postgraduate year (PGY) & $33(36 \%)$ \\
1 & $17(18 \%)$ \\
2 & $24(26 \%)$ \\
3 & $8(9 \%)$ \\
4 & $5(5 \%)$ \\
5 & $2(2 \%)$ \\
6 & $3(3 \%)$ \\
7 & \\
Training program ${ }^{\text {a }}$ & $25(80.6 \%)$ \\
Family medicine & $23(60.5 \%)$ \\
Internal medicine & $13(65.0 \%)$ \\
Radiology & $10(71.4 \%)$ \\
Transitional year & $11(40.7 \%)$ \\
Cardiology fellowship & \\
Obstetrics and gynecology & $7(62.2 \%)$ \\
Hospice/palliative care fellowship & $2(100 \%)$ \\
Gastrointestinal fellowship & $1(33.3 \%)$ \\
Surgical oncology fellowship & $0(0 \%)$ \\
Total & $92(62.2 \%)$ \\
\hline
\end{tabular}

aPercentages, other than for "Total," were calculated within each program group.

b"Cardiology fellowship" includes all cardiology subspecialty fellowship programs. 
Table 2. Previous COVID-19 Testing and Exposure Among All Respondents Throughout Any Time Period in Study $(\mathrm{N}=92)$

\begin{tabular}{|c|c|}
\hline Known testing and exposure to COVID-19 & $\mathrm{n}(\%)$ \\
\hline \multicolumn{2}{|l|}{ Previous testing } \\
\hline Tested for acute COVID-19 & $17(18.5 \%)$ \\
\hline Tested positive for acute COVID-19 & $1(1.1 \%)$ \\
\hline \multicolumn{2}{|l|}{ Household exposure } \\
\hline Had a household member with known exposure & $20(21.7 \%)$ \\
\hline Exposed by a confirmed positive household member ${ }^{a}$ & $4(4.5 \%)$ \\
\hline \multicolumn{2}{|l|}{ Patient exposure by training program ${ }^{b}$} \\
\hline Family medicine & $23(92.0 \%)$ \\
\hline Internal medicine & $20(87.0 \%)$ \\
\hline Radiology & $6(46.2 \%)$ \\
\hline Transitional year & $10(100 \%)$ \\
\hline Cardiology fellowship ${ }^{c}$ & $9(81.8 \%)$ \\
\hline Obstetrics and gynecology & $6(85.7 \%)$ \\
\hline Hospice/palliative care fellowship & $1(50.0 \%)$ \\
\hline Gastrointestinal fellowship & $1(100 \%)$ \\
\hline Total & $76(82.7 \%)$ \\
\hline \multicolumn{2}{|l|}{ Other exposure } \\
\hline Outside work and home & $30(32.6 \%)$ \\
\hline \multicolumn{2}{|l|}{ Any exposure ${ }^{d}$} \\
\hline Household member or patient or other & $92(100 \%)$ \\
\hline \multicolumn{2}{|l|}{ Travel } \\
\hline International & $14(15.2 \%)$ \\
\hline Domestic & $55(59.8 \%)$ \\
\hline
\end{tabular}

${ }^{a}$ A confirmed positive household member was determined by clinical signs and symptoms only. There were no cases of household exposure to a COVID-19-positive person where the positive status was confirmed by a COVID-19 test.

${ }^{b}$ Percentages, other than for "Total," were calculated within each program group.

"Cardiology fellowship" includes all cardiology subspecialty fellowship programs.

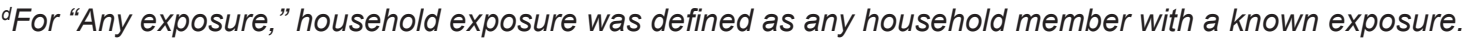

did not take the $\mathrm{Ab}$ test). When asked if they wished to be seropositive, 59 of 92 (64\%) responded affirmatively. Primary reasons for wanting to test seropositive (openended question) included having immunity to COVID-19 $(n=42,71 \%)$, peace of mind $(n=17,29 \%)$, and concern about an asymptomatic infection or possible transmission $(\mathrm{n}=14$, 24\%). Other reasons included lower risk of transmission $(\mathrm{n}=8,14 \%)$, protect family $(\mathrm{n}=7,12 \%)$, ability to donate plasma $(n=4,7 \%)$, comfort treating patients $(n=4,7 \%)$, confirmation of previous COVID-19 symptoms ( $\mathrm{n}=3,5 \%)$, and exemption from vaccination $(\mathrm{n}=1,2 \%)$.

\section{Seroprevalence}

$\mathrm{Ab}$ testing was performed on 75 individuals $(51 \%$ of all potential subjects, $82 \%$ of those surveyed) (Figure 1). One individual tested seropositive $(1.3 \%$; $95 \% \mathrm{CI}$ :
0.0-3.9). This trainee had not been previously diagnosed with COVID-19, was not previously tested for acute COVID-19, reported no COVID-19-related symptoms for the duration of the study period, and had no underlying health conditions (as defined in Table 3 ). Approximately 64 hours of COVID-19 pay was given to this participant during March 9, 2020, to April 5, 2020. There was no known domestic or international travel for this participant, who lived in a household with 3 other persons who had not tested positive for COVID-19 during the study period. There was no known exposure outside of work and home.

All remaining $74 \mathrm{Ab}$-tested subjects had index values well below the cut-off of 1.4 (Figure 3 ). The association analysis planned in the study design was not performed due to there being a single positive test result. 
Table 3. Patient Encounters With COVID-19-Positive Patients by Training Program

\begin{tabular}{lcc}
\hline Training program & $\begin{array}{c}\text { Mean encounters per } \\
\text { respondent (SD) }\end{array}$ & $\begin{array}{c}\text { Total encounters } \\
\text { within program (\%) }\end{array}$ \\
\hline Family medicine & $10.1(8.9)$ & $252(19.5 \%)$ \\
Internal medicine & $29.7(30.2)$ & $653(50.6 \%)$ \\
Radiology & $3.7(7.7)$ & $48(3.7 \%)$ \\
Transitional year & $15.8(10.8)$ & $158(12.2 \%)$ \\
Cardiology fellowship & $7.5(8.8)$ & $82(6.4 \%)$ \\
Obstetrics and gynecology & $11.1(6.4)$ & $78(6.0 \%)$ \\
Hospice/palliative care fellowship & $9.5(13.4)$ & $19(1.5 \%)$ \\
Gastrointestinal fellowship & - & $1(0.10 \%)$ \\
Total encounters & & $1291(100 \%)$ \\
\hline
\end{tabular}

a"Cardiology fellowship" includes all cardiology subspecialty fellowship programs.

$S D$, standard deviation.

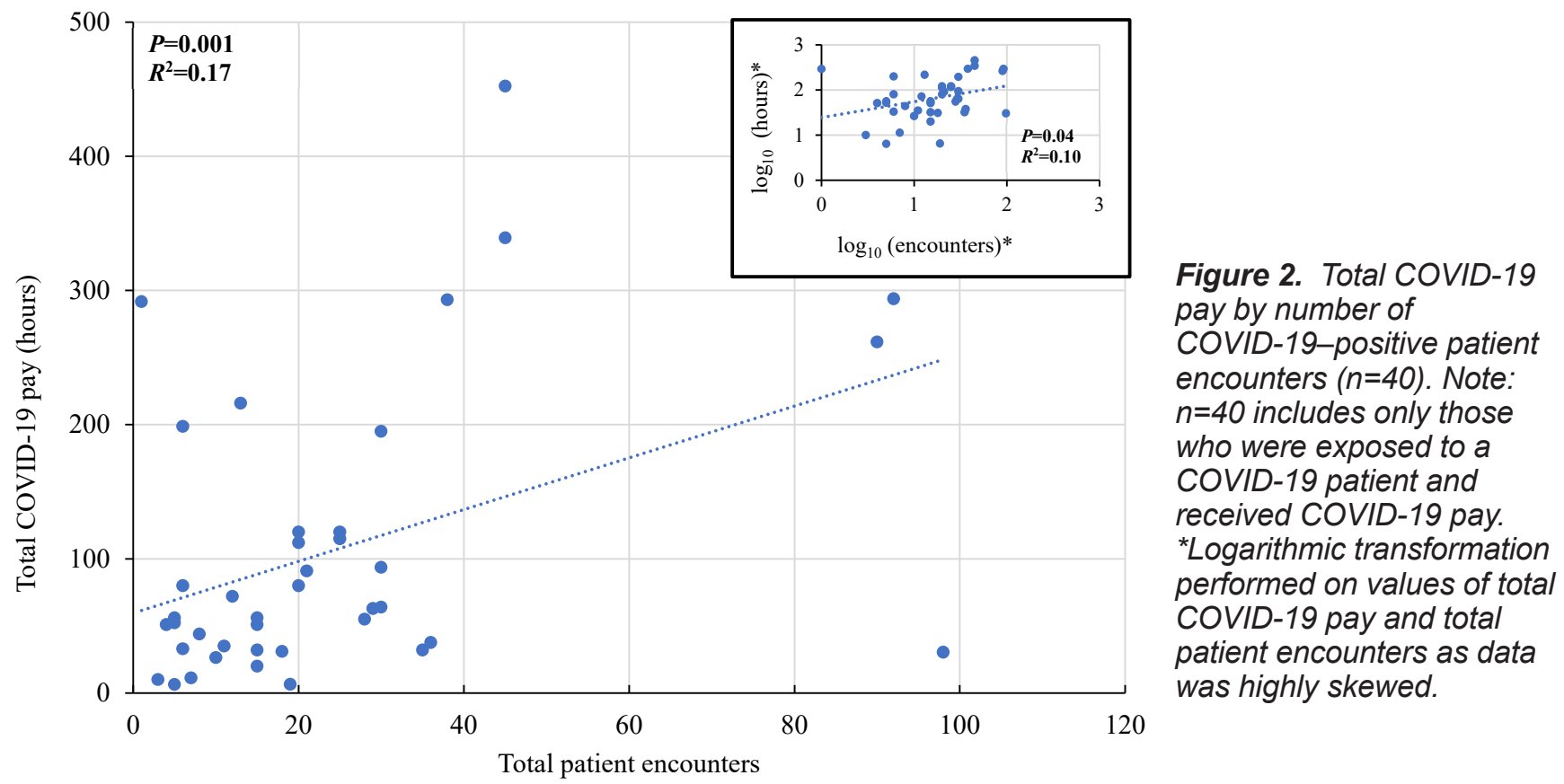

\section{DISCUSSION}

At the time of this writing, we found no published reports of COVID-19 seroprevalence solely among resident and fellow physicians based in the United States. COVID-19 IgG seroprevalence was quite low in our population of residents and fellows $(1.3 \% ; 95 \%$ CI: 0.0-3.9) despite various and universal self-report of exposures. There are many possible explanations for this prevalence rate, which was similar to the reported $3.7 \%$ Ab-positive rate among 2456 Milwaukee-based staff in our same integrated health system. ${ }^{24} \mathrm{Ab}$ rates among those with clinical roles (residents and fellows not delineated) from the combined Wisconsin and Illinois portions of our health system was $3.5 \%$, compared to $3.0 \%$ in nonclinical staff, ${ }^{24}$ both of which are similar to our study's findings. Our study population's Ab prevalence rate was lower than the $6.5 \%$ reported for systemwide staff deemed "COVID-19 clinical" 24 and (nonsignificantly) lower than the 7.0\% (95\% CI: 2-20) prevalence found in 43 echocardiography and stress laboratory staff at the primary medical center that also hosts our study's medical trainees. ${ }^{25}$ 


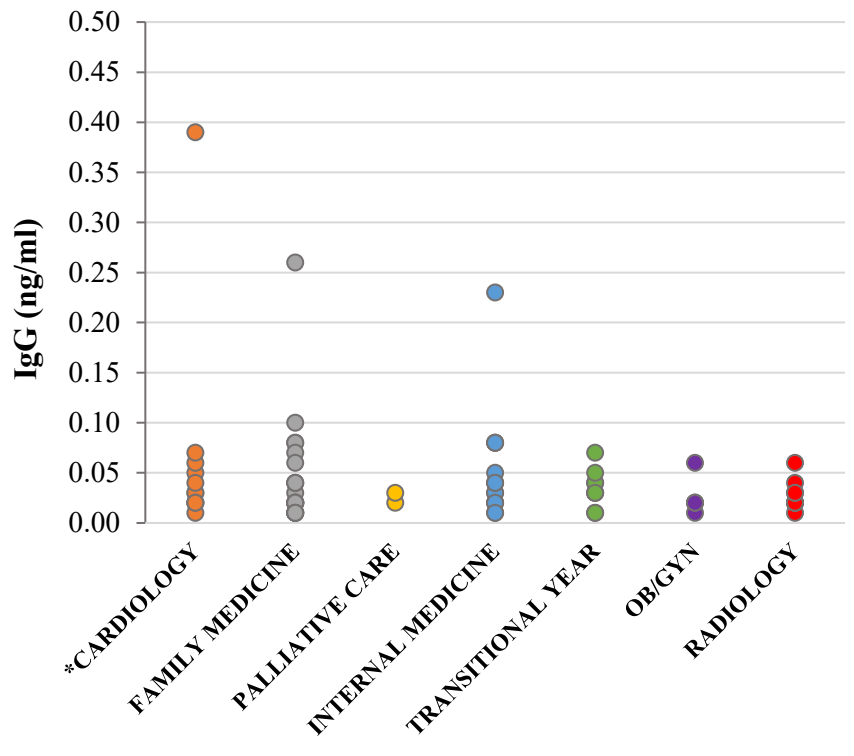

Figure 3. Negative IgG values by training program for all participants who received an antibody test. ${ }^{*}$ Cardiology includes all cardiology subspecialty fellowship programs. Gastrointestinal fellowship was excluded as there was only 1 participant.

Our results are similar to the $<1 \%$ seroconversion (utilizing the IgG ELISA [EUROIMMUN] and Elecsys ${ }^{\circledR}$ [Roche Diagnostics] assays) among well-protected health care workers not known to have had acute COVID-19 infection following an outbreak in a German perinatal center ${ }^{26}$ and to the $2.9 \%$ seroconversion among internal/ family medicine physicians and $0 \%$ conversion among pulmonary/critical care physicians in Chicago. ${ }^{27}$ The latter study was performed during a similar time period as ours and used the same $\mathrm{Ab}$ test (index value cut-off not reported), but it did not differentiate residents and fellows. That study had an overall Ab positivity rate among all patient-facing and non-patient-facing health care workers of $4.3 \%$, among whom $17.5 \%$ believed they had experienced nonhospital COVID-19 exposure. ${ }^{27}$ Therefore, COVID-19 seroconversion may be low in properly protected residents and fellows and proportional to other protected health care workers.

Our seroprevalence rate was below that of physicians (6.1\%, not specific for trainees) in 27 hospitals in the Detroit, Michigan, area tested during a similar time period utilizing VITROS (Ortho Clinical Diagnostics). ${ }^{28}$ Of various units, seroprevalence was highest among physicians in hospital emergency departments $(8.2 \%)$. Consistent use of N95 and surgical facemasks decreased the likelihood of seropositivity among hospital workers in this study, with household COVID-19-positive exposures increasing likelihood of seropositivity. ${ }^{28}$
Talbot and colleagues performed a cross-sectional study of 474 health care workers at a single New York hospital utilizing a survey and nucleocapsid-detecting COVID-19 $\operatorname{IgM} / \mathrm{IgG} \mathrm{Ab}$ assay (DPP ${ }^{\circledR}$, Chembio Diagnostics, Inc.). ${ }^{29}$ Various physicians were included, but residents and fellows were not delineated. Seroprevalence was lower (12.7\%) in physicians with "frontline" potential COVID-19 patient exposure than in "other" physicians (16.5\%). Overall, Ab prevalence was lower $(14.2 \%)$ among health care workers with high time exposure to COVID-19 patients than in those with minimal time exposure $(18.9 \%)$. The authors concluded that their overall seropositivity $(16.9 \%)$ was similar to the general population of New York during that time (14\%) and that COVID-19 infection among health care workers may result from community rather than occupational exposure. ${ }^{29} \mathrm{~A}$ recent systematic review indicated that COVID-19 seroprevalence is generally higher among those 1) working in a COVID-19 unit, 2) having shortage of PPE, and 3) having known or suspected household COVID-19 contact. ${ }^{7}$ It is unclear if our study's comparatively lower prevalence rate was due to relatively lower COVID-19 patient census, fewer COVID-19 patient contact hours, better or more familiar PPE usage, different physician habits, or other factors. A minority of our subjects reported household contact exposure. While estimates vary widely, ${ }^{30}$ a study of Wisconsin and Tennessee households during the approximate time of our study showed an overall secondary household infection rate of $53 \% .^{31}$

Another possible explanation for our study's low prevalence is that some number of our subjects had become acutely infected with COVID-19 but did not have significant $\mathrm{Ab}$ levels at the time of testing (perhaps as much as 4 months following exposure). While there are reports of waning $\operatorname{IgG} \mathrm{Ab}$ beyond 3 months from acute illness onset, especially in milder disease, ${ }^{17,18}$ a study of 1215 COVID-19 patients in Iceland suggests that $\mathrm{Ab}$ levels do not decline within 4 months of diagnosis. ${ }^{19}$ Studies from Portugal and New York report Ab detection for up to 5-6 months. ${ }^{32,33}$ Thus, it is likely that Ab would persist in previously infected subjects until the time of assay in our study. Conversely, subjects who had become infected with COVID-19 within 2-3 weeks prior to the $\mathrm{Ab}$ test, particularly with mild disease, may have yielded a negative result for this IgG test. ${ }^{34}$ Based on our health system's COVID-19 pay data, this would be expected to be a small number of potential subjects.

Regarding attitudes held by residents and fellows on prior infection, more than half of the respondents noted they hoped their Ab test would come back positive. Most of those reportedly hoping for a positive test explained that stance as wanting evidence of personal immunity, even though national COVID-19 guidance advised that Ab testing not be considered a reliable measure of immunity status. 
Regarding the specific ARCHITECT Ab assay employed in this study, it compares favorably to other commercial assays in prior studies, ${ }^{35-39}$ with up to $98.9 \%$ agreement for consensus negative and $99.7 \%$ for consensus positive tests, as compared to other assays. ${ }^{36,39}$

\section{Limitations}

In addition to the aforementioned discussion points, limitations of our study include a relatively modest sample of resident and fellow physicians in a single metropolitan area, reliance on subject recall, and inability to perform subset analysis due to having only a single positive subject. Additionally, not all ACGME program disciplines were represented in our institution. These issues limit generalizability. Acute COVID-19 testing was not performed on most subjects in order to correlate with our very low Ab prevalence. Therefore, our results must be put in context of the local community prevalence (approximately $1 \%$ cumulative acute cases) at the time of the study. ${ }^{40}$ An updated study by the Survey of the Health of Wisconsin revealed that $\mathrm{Ab}$ prevalence among Wisconsin participants increased 4-5-fold between summer $(1.6 \%)$ and fall $(6.8 \%)$ of 2020 , with reported prevalence of $9.2 \%$ in southeastern Wisconsin in the latter time period. ${ }^{41}$

\section{CONCLUSIONS}

COVID-19 IgG seroprevalence was quite low in this population of U.S. Midwest, urban-based resident and fellow physicians despite all subjects reporting various potential exposures to infectious patients. As these findings were similar to those of other reported regional $\mathrm{Ab}$ rates among well-protected hospital staff, it appears that secondary acquisition of COVID-19 may remain low (and similar to community levels, as previously suggested ${ }^{29}$ ) in properly protected residents and fellows regardless of clinical activities.

\section{Patient-Friendly Recap}

- Physicians-in-training, such as residents and specialty fellows, are variously exposed to patients with COVID-19 and must be protected from catching the disease.

- The authors surveyed resident and fellow physicians about their risk factors and potential exposures to COVID-19 during early months of the pandemic in Milwaukee, Wisconsin.

- Only 1 of 75 tested residents and fellows had evidence of prior COVID-19 disease based on a serum antibody (nucleocapsid protein) test.

\section{Acknowledgments}

We thank all of the resident and fellow physicians who participated in this study and the kind cooperation of ACL Laboratories.

\section{Author Contributions}

Study design: all authors. Data acquisition or analysis: Baumgardner, Schwank, Kram, La Fratta. Manuscript drafting: Baumgardner, Schwank, Kram. Critical revision: all authors.

\section{Conflicts of Interest}

None.

\section{Funding Sources}

Antibody testing for this study was funded by the Aurora Health Care Foundation.

\section{References}

1. Centers for Disease Control and Prevention. COVID-19. Accessed December 20, 2021. https://www.cdc.gov/ coronavirus/2019-ncov/index.html

2. Pedersen SF, Ho YC. SARS-CoV-2: A storm is raging. $J$ Clin Invest. 2020;130:2202-5. CrossRef

3. Wilder-Smith A, Chiew CJ, Lee VJ. Can we contain the COVID-19 outbreak with the same measures as for SARS? Lancet Infect Dis. 2020;20:e102-7. CrossRef

4. Li R, Pei S, Chen B, et al. Substantial undocumented infection facilitates the rapid dissemination of novel coronavirus (SARSCoV-2). Science. 2020;368:489-93. CrossRef

5. Baker MG, Peckham TK, Seixas NS. Estimating the burden of United States workers exposed to infection or disease: a key factor in containing risk of COVID-19 infection. PLoS One. 2020;15(4):e0232452. CrossRef

6. He X, Lau EHY, Wu P, et al. Temporal dynamics in viral shedding and transmissibility of COVID-19. Nat Med. 2020;26:672-5. CrossRef

7. Galanis P, Vraka I, Fragkou D, Bilali A, Kaitelidou D. Seroprevalence of SARS-CoV-2 antibodies and associated factors in healthcare workers: a systematic review and metaanalysis. J Hosp Infect. 2021;108:120-34. CrossRef

8. Gallagher MJ, Bloomingdale R, Berman AD, Williamson BD, Dixon SR, Safian RD. Strategic deployment of cardiology fellows in training using the Accreditation Council for Graduate Medical Education coronavirus disease 2019 framework. $J$ Am Heart Assoc. 2020;9(14):e017443. CrossRef

9. Potts JR 3rd. Residency and fellowship program accreditation: effects of the novel coronavirus (COVID-19) pandemic. J Am Coll Surg. 2020;230:1094-7. CrossRef

10. Dennis B, Hight A, Kendrick D, et al. Knowing your team: rapid assessment of residents and fellows for effective horizontal car delivery in emergency events. J Grad Med Educ. 2020;12:272-9. CrossRef

11. Juprasert JM, Gray KD, Moore MD, et al. Restructuring of a general surgery residency program in an epicenter of the coronavirus disease 2019 pandemic: lessons from New York City. JAMA Surg. 2020;155:870-5. CrossRef

12. Nassar AH, Zem NK, McIntyre LK, et al. Emergency restructuring of a general surgery residency program during the coronavirus disease 2019 pandemic: the University of Washington experience. JAMA Surg. 2020;155:624-7. CrossRef 
13. Virarkar M, Jensen C, Javadi S, Saleh M, Bhosale PR. Radiology education amid COVID-19 pandemic and possible solutions. J Comput Assist Tomogr. 2020;44:472-8. CrossRef

14. An TW, Henry JK, Igboechi O, et al. How are orthopaedic surgery residencies responding to the COVID-19 pandemic? An assessment of resident experiences in cities of major virus outbreak. J Am Acad Orthop Surg. 2020;28:e679-85. CrossRef

15. Winter AK, Hegde ST. The important role of serology for COVID-19 control. Lancet Infect Dis. 2020;20:758-9. CrossRef

16. Perera RA, Mok CK, Tsang OT, et al. Serological assays for severe acute respiratory syndrome coronavirus 2 (SARSCoV-2), March 2020. Euro Surveill. 2020;25(16):2000421. CrossRef

17. Ibarrondo FJ, Fulcher JA, Goodman-Meza D, et al. Rapid decay of anti-SARS-CoV-2 antibodies in persons with mild Covid-19. N Engl J Med. 2020;383:1085-7. CrossRef

18. Ripperger TJ, Uhrlaub JL, Watanabe M, et al. Orthogonal SARS-CoV-2 serological assays enable surveillance of lowprevalence communities and reveal durable humoral immunity. Immunity. 2020;53:925-33.e4. CrossRef

19. Gudbjartsson DF, Norddahl GL, Melsted P, et al. Humoral immune response to SARS-CoV-2 in Iceland. $N$ Engl J Med. 2020;383:1724-34. CrossRef

20. Clapham H, Hay J, Routledge I, et al. Seroepidemiologic study designs for determining SARS-COV-2 transmission and immunity. Emerg Infect Dis. 2020;26:1978-86. CrossRef

21. Harris PA, Taylor R, Thielke R, Payne J, Gonzalez N, Conde JG. Research electronic data capture (REDCap) - a metadatadriven methodology and workflow process for providing translational research informatics support. J Biomed Inform. 2009;42:377-81. CrossRef

22. Harris PA, Taylor R, Minor BL, et al. The REDCap consortium: building an international community of software platform partners. J Biomed Inform. 2019;95:103208. CrossRef

23. Menni C, Valdes AM, Freidin MB, et al. Real-time tracking of self-reported symptoms to predict potential COVID-19. Nat Med. 2020;26:1037-40. CrossRef

24. Fitzpatrick V, Rivelli A, Blair C, Copeland K, Richards J. Disparities in seroprevalence of SARS-CoV-2 immunoglobulin antibodies in a large Midwestern health care system. Public Health Rep. 2021;136:361-7. CrossRef

25. Jain R, Kroboth S, Ignatowski D, Khandheria BK. Seroprevalence of SARS-CoV-2 antibody in echocardiography and stress laboratory. J Patient Cent Res Rev. 2021;8:146-50. CrossRef

26. Malfertheiner SF, Brandstetter S, Roth S, et al. Immune response to SARS-CoV-2 in health care workers following a COVID-19 outbreak: a prospective longitudinal study. J Clin Virol. 2020;130:104575. CrossRef

27. Wilkins JT, Gray EL, Wallia A, et al. Seroprevalence and correlates of SARS-CoV-2 antibodies in health care workers in Chicago. Open Forum Infect Dis. 2020;8(1):ofaa582. CrossRef

28. Akinbami LJ, Vuong N, Petersen LR, et al. SARS-CoV-2 seroprevalence among healthcare, first response, and public safety personnel, Detroit metropolitan area, Michigan, USA, May-June 2020. Emerg Infect Dis. 2020;26:2863-71. CrossRef
29. Talbot LR, Romeiser JL, Spitzer ED, et al. Prevalence of IgM and IgG antibodies to SARS-CoV-2 in health care workers at a tertiary care New York hospital during the Spring COVID-19 surge. Perioper Med (Lond). 2021;10(1):7. CrossRef

30. Fung HF, Martinez L, Alarid-Escudero F, et al. The household secondary attack rate of severe acute respiratory syndrome coronavirus 2 (SARS-CoV-2): a rapid review. Clin Infect Dis. 2021;73(Suppl 2):S138-45. CrossRef

31. Grijalva CG, Rolfes MA, Zhu Y, et al. Transmission of SARSCOV-2 infections in households - Tennessee and Wisconsin, April-September 2020. MMWR Morb Mortal Wkly Rep. 2020;69:1631-4. CrossRef

32. Figueiredo-Campos $\mathrm{P}$, Blankenhaus B, Mota C, et al. Seroprevalence of anti-SARS-CoV-2 antibodies in COVID-19 patients and healthy volunteers up to 6 months post disease onset. Eur J Immunol. 2020;50:2025-40. CrossRef

33. Wajnberg A, Amanat F, Firpo A, et al. Robust neutralizing antibodies to SARS-CoV-2 infection persist for months. Science. 2020;370:1227-30. CrossRef

34. Hu WT, Howell JC, Ozturk T, et al. Antibody profiles according to mild or severe SARS-CoV-2 infection, Atlanta, Georgia, USA, 2020. Emerg Infect Dis. 2020;26:2974-8. CrossRef

35. Brochot E, Demey B, Handala L, François C, Duverlie G, Castelain S. Comparison of different serological assays for SARS-CoV-2 in real life. J Clin Virol. 2020;130:104569. CrossRef

36. Prince HE, Givens TS, Lapé-Nixon M, et al. Detection of SARS-CoV-2 IgG targeting nucleocapsid or spike protein by four high-throughput immunoassays authorized emergency use. J Clin Microbiol. 2020;58:e10742-20. CrossRef

37. Nguyen NN, Mutnal MB, Gomez RR, et al. Correlation of ELISA method with three other automated serological tests for the detection of anti-SARS-CoV-2 antibodies. PLoS One. 2020;15(10):e0240076. CrossRef

38. Naaber P, Hunt K, Pesukova J, et al. Evaluation of SARSCoV-2 IgG antibody response in PCR positive patients: comparison of nine tests in relation to clinical data. PLoS One. 2020;15(10):e0237548. CrossRef

39. Suhandynata RT, Hoffman MA, Kelner MJ, McLawhon RW, Reed SL, Fitzgerald RL. Multi-platform comparison of SARSCoV-2 serology assays for the detection of COVID-19. J Appl Lab Med. 2020;5:1324-36. CrossRef

40. Milwaukee County COVID-19 Epidemiology Intel Team. Milwaukee County COVID-19 data summary. Updated June 4, 2020; accessed January 25, 2021. https://county. milwaukee.gov/files/county/COVID-19/EPI-Data-Reports/ WeeklyReport June4.pdf

41. University of Wisconsin School of Medicine and Public Health. New statewide data show evidence of four-fold increase in recent COVID-19 infections. Last updated December 23, 2020; accessed January 25, 2021. https://www.med.wisc.edu/ news-and-events/2020/december/wisconsin-data-show-recentcovid-infection-surge/

(C) 2022 Advocate Aurora Health, Inc. 